\title{
Ethical Leadership, Ethical Leadership Climate and Employee Moral Effectiveness: A Social Learning Perspective
}

\author{
Freida Ozavize Ayodele1, Hasnah Binti Haron,2,3, and Ishak Ismail 2,3 \\ ${ }^{1}$ Department of Accounting and Finance, UCSI University, 56000 Kuala Lumpur, Malaysia \\ ${ }^{2}$ Faculty of Industrial Management, Universiti Malaysia Pahang, 26300 Gambang, Pahang, \\ Malaysia \\ ${ }^{3}$ FIM Governance and Integrity Center, 26300 Gambang,, Pahang Malaysia
}

\section{Abstract}

The study employs social learning theory (SLT) to investigate the impact of virtue and tone based ethical leadership on the subordinates moral outcome in institutions. Data were collected from a survey of 182 academic staff in a university in Africa. The partial least squares structural equation modeling (PLS-SEM) is the data analytic technique employed to test the research model. The findings suggest that virtue-based academic ethical leadership and ethical leadership climate positively influence employee moral effectiveness. Academic ethical leadership was found to have a profound indirect significant influence on employee moral effectiveness and academic ethical leadership. The research is substantial and would be of interest to educational policymakers, academic leaders and government in resolving ethical issues.

Keywords: social learning theory, leadership, employee effectiveness.

\section{Introduction}

Academic misconduct is any action that results in creating an unfair academic advantage for oneself to the disadvantage of other members of the academic community. Academic employee moral misconduct is potential harm to the institution irrespective of the benefits to be gained by such employee (Ayodele, Yao, \& Haron, 2018). To this end, organizations are keen on mechanisms that will enhance the moral behavior of their employees to mitigate the undesirable effects of employee misconduct(Abboud, Wu, Pedneault, Stohr, \& Hemmens, 2017). Employee moral behavior is the ability of the employee to form the right opinion about acceptable principles of right or wrong behavior based on applicable ethical standards (He, Zhu, \& Zheng, 2014). The inner sense of what is right or wrong in one's conduct or motives, impelling employee toward the right actions (Moore, 2015). Employee ethical decision making in institutions are 
employee, the decision to embark or not on morally acceptable conducts may have more to do with the moral consciousness created by top management than solely individual factors (Bagozzi, Sekerka, \& Sguera, 2018). The observed moral actions of senior management by subordinates can foster the inclination of subordinates to follow the dictates of laid down rules on ethical issues(Sousa \& van Dierendonck, 2017; Walker \& Jackson, 2017).

Moreover, there is the saying that habits form character. As such, this study believes that the moral practices of academic leaders may tend to shape the morality and integrity of the academic subordinates they are directing or leading. Obviously, in institutions, leaders are a source of employee ethical guidance in the workplace (Hyytinen \& Löfström, 2017; Walker \& Jackson, 2017). The reason is that ethical leaders are morally obligated to be concerned with matters of integrity in their decision-making as practicing moral preachers and moral motivators (Hoch, Bommer, Dulebohn, \& Wu, 2018; Leroy, Segers, van Dierendonck, \& den Hartog, 2018). However, the upsurge in unethical practices of academic workings in different institutions across the continent is worrisome (Ayodele et al., 2018). The wholesale usage of the intellectual materials produced by others without acknowledging its sources by academic is on the rise particularly in Africa where majority of the journals published are paper-based. Due to the belief that leadership virtues contribute to explain the actions of their subordinates in a context (Riggio, Zhu, Reina, \& Maroosis (2010)), leadership and the ethical tone created by those in top management might help to address the rise in unethical academic practices if emphasized.

In literature, extensive important works employ different perspectives about ethical leadership. Lewis (2017) and Hoch et al. (2018) see ethical leadership from a transformative perspective; Sidani \& Rowe (2018) studied ethical leadership from an authentic viewpoint; Leroy et al. (2018) argued ethical leadership from a transactional perspective while Walumbwa et al. (2011) viewed ethical leadership from a charismatic perspective. However, some authors like Riggio, Zhu, Reina, \& Maroosis (2010) criticized most of the current aspects of moral leadership in that they could lead to unethical social influence due to ethical relativism. More so, unlike the virtue and tone-based perspectives to explaining the effect of ethical leadership on employee moral effectiveness in the African context, other existing views have been well researched in the literature using social learning perspective (Brown \& Treviño, 2006). Hence, ethical policymakers in the African context are not well abreast with the potential antecedents of virtue based academic ethical leadership and ethical leadership tone on employee moral effectiveness. Besides, the virtue-based perspective is grounded in prior studies only that consistency 
of moral character is more emphasized. Thus, within the broad perspectives, imbibed as dimensions of ethical leadership in this study are the virtue-based viewpoint that believed that virtues describe ethical leadership and the ethical tone perspectives argued by Haron et al. (2017).

Despite, the interesting propositions on virtue and tone-based perspective, there is little understanding of the impact of ethical leadership on employee moral performance (moral positioning) based on the views. The reason is that the moral status of a person is important in making ethical decisions (Akere, Sevell, \& Stewart, 2016; Rest \& Thoma 1985). Meanwhile, Haron et al. (2017) have consistently argued that the ethical tone fostered by organizational leadership is an essential factor in curbing unethical conducts in organizations. Drawing from Haron et al. (2017) work, there is the possibility that the virtue-based academic ethical leader might stimulate moral climate that positions employee to make necessary moral choices. The question that comes to mind is that 'does the tone created by virtue-based ethical leaders (ethical leadership climate) a valid mechanism through which virtue-based ethical leaders impacts employee moral effectiveness in the workplace'? Secondly, does ethical leadership climate contribute to explain the moral outcomes of subordinates in institutions?

This study believes that virtue-based educational leadership plays a possible role in shaping the ethical conducts of academic lecturers and creating the enabling climate for moral decisions in academics. The aim of the study is to explore the linkages between academic ethical leadership, ethical leadership climate and academic employee moral effectiveness. The study proposes social learning theory (SLT) as a theoretical basis for understanding the predictive links between academic ethical leadership, academic ethical leadership climate and academics employee moral effectiveness (outcome) in a model. The empirical evidence from this type of study will provide new insight to educators on how educational ethical leadership can create an ethical climate for academic subordinates to indulge in morally acceptable behavior in institutions, the African context in particular. Consequently, the research is significant as it contributes to ethical perspectives in literature and advances knowledge on the links that can be employed to reduce unethical academic practices in academic research. This study also directs practitioners and educational, ethical lawmakers attention to the importance of stimulating a virtue-based environment for the enhanced moral performance of both the top management academic ethical leaders and subordinate academic employee. Hence, the study would be of interest to educational stakeholders in diverse positions, education policy-makers, and government and the social learning theory utilized may further inform theoretical development in future studies. 


\section{Literature Review}

Brown \& Treviño (2006) defined ethical leadership as the demonstration of normatively appropriate conducts through individual actions and interpersonal dealings and the advancement of such behavior to followers via two-way interaction, strengthening, and decision making. Kalshoven, Den Hartog, \& De Hoogh (2011) opined that a set of accepted beliefs drives ethical leaders conducts and appropriate judgment that has been stipulated as morally right by instituted higher authorities and the society rather than selfish interest. However, due to moral absolutism associated with the virtuebased perspective to ethical leadership, it is the virtue-based perspective that is taken in this study. Riggio et al. (2010) argued that ethical leadership is the consistent makeup or virtues of the individual. By virtue, Riggio et al. (2010) imply all times practiced morals and that prudence, fortitude, temperance, and justice reflects moral virtues that transform an individual attitude. Virtue-based leaders are obliged to convey the interest of stakeholders on ethical matters by socially influencing the subordinate's moral status. Even Aristotle (2006) argued that the spirit of morality is awakened in individuals only through the witness and conduct of a moral person. Consequently, awakened in subordinates is the spirit of making ethical decisions by the conduct and virtues of moral leaders.

Moral leaders can influence the employees through 'the spirit' which connotes creating an enabling environment for them to do the right things by carrying out the moral action itself and possession of moral virtues. Besides, role modeling is a key aspect of a leader as employees can learn expected behavior, reward, and punishment through role modeling (Sidani \& Rowe, 2018). Thus, in this context that academic leadership might possess the power to affect the ethical behavioral outcome of employees (moral status of the employee) and ethical climate outcomes in institutions. Drawing from Riggio et al. (2010), for academic leaders to be perceived as ethical leaders and to influence ethics-related outcomes, they must be perceived as prudent, credible, and legitimate by the would-be followers. It is based on the perceived virtues that leaders are morally obligated to communicate to employees about acceptable standards, conducts and values and motivates the staff to comply accordingly (Bouckenooghe, Zafar, \& Raja, 2015). This study mentions that virtue-based leaders create an ethical climate for subordinates to act by their morally exemplifying behavior in the realizations of organizational objectives and due to the virtues, they possessed. The ethical tone created by leaders can be likened to the learning environment while the virtues possessed by the leaders likened to the observed moral that stimulates morale actions according to social 
learning theory. Thus, the social learning perspective is employed to empirically test the proposed relationships between academic ethical leadership (AEL), ethical leadership climate (ELC) and employee moral outcome (EMO) in the study

\subsection{Social learning theory (SLT) and research theoretical frame- work}

Social learning theory (SLT), is a theory of social behavior which suggest that new behaviors can be acquired or imitated by observation and learning (Brown, Treviño, \& Harrison, 2005). Drawing from SLT, observed attitudes from leaders and moral learning climate contribute to the follower's moral development (Brown \& Treviño, 2006). Leaders possess the power to influence the actions of employees either in a morally acceptable way or otherwise (Reb, Narayanan, \& Chaturvedi, 2014). Leaders in academics that are ethically inclined will be careful to emphasize morality in the way institutional academic $\mathrm{KPI}$ is set and realized through exemplifying attitudes. Giving unrealistic and unattainable targets to academic subordinates only provokes unethical conducts towards publishing goal attainment especially with those with morally weak tendencies. Ethical academic leaders are not expected to be preaching publish or perish spirit among the subordinates rather empathize and be temperate with the employees in their genuine effort to publish amidst difficulties (Grimes, Bauch, loannidis, \& Grimes, 2018). This way academic leaders can reduce the pressure to indulge in unethical decisions and actions. Besides, Hunter et al. (2013) indicated a positive relationship between ethical leadership and ethical conduct of employees or subordinates. Although some might argue that to indulge or not in ethical academic actions is personal, this study argued that academic leaders could play a significant role in the academic ethical conduct of the employee in universities. As such, academic policy-makers can manipulate the link to reduce misconduct among academic employees in four different but interrelated psychological aspects argued by Rest \& Thoma (1985). The psychological aspects because Rest \& Thoma (1985) indicated that the moral status aspect (judgment, character, sensitivity, and motivation) of an individual must be influenced to behave ethically. Surprisingly, the influence of academic ethical leadership on academic employee moral outcome using social learning theory is currently under-researched. The study, therefore, proposes the following hypothesis to test the identified relationship:

H1: Academic ethical leadership positively influences employee moral outcome

In African universities, leaders communicate matters on ethics including the reward and promotion of ethical behaviors along with punishments associated with unethical 
conducts among subordinates. When top academic leaders exemplify to clarifies the role of employees and performance expectation on ethical related issue and dilemma in compliance with established ethical standards, expedited is the platform (which is the spirit according to Aristotle (2006) to embark on moral action by subordinates. Drawing from the social learning theory (SCT), learning orientation environment is stimulated through such observations of morally acceptable behaviors and fairness demonstrated by the leaders in meting out appropriate punishment and rewards. Brown et al. (2005) suggested that leaders create an ethical climate for employee moral effectiveness in organizations through the provision of ethical guidance. Similarly, De Hoogh \& Den Hartog (2008) in their empirical work argued that ethical leader's role modeling creates enabling environment to employees to perform moral actions without fear of being reprimanded unjustly. Specifically, Riggio et al. (2010) argued that it is characteristics (virtues) that create a moral leader or makes the leader exhibit the desired moral actions or dictate the right ethical tone in the workplace. Besides, attributed to the presence of high ethical standards awareness and virtues possessed enabled by ethical leaders in the cognitive moral development and ethical decision-making behavior of the employee (Riggio, Zhu, Reina, \& Maroosis, 2015; Hasnah et al., 2017). Consequently, this study posits that activated through the demonstration of acceptable ethical virtues by academic leaders as practicing preachers, the opportunity for academic employees to conduct themselves most ethically, thereby enhancing subordinate ethical behavior. Surprisingly, sparingly investigated in the literature is the link between academic ethical leadership and ethical leadership climate and the indirect link between academic ethical leadership and employee moral positioning using SLT. Thus, proposed in the study is the following hypotheses:

H2: Academic ethical leadership positively influences ethical leadership climate

H3: Ethical leadership climate positively influences employee moral outcome

H4: Academic ethical leadership positively influences employee moral outcome through academic ethical climate.

Figure 1 below is the proposed research theoretical framework for the study. Based on SLT, academic ethical leadership is expected to positively impact employee moral outcome either directly or indirectly via ethical climate while the ethical climate is expected to influence the employee morale outcome in the stud 


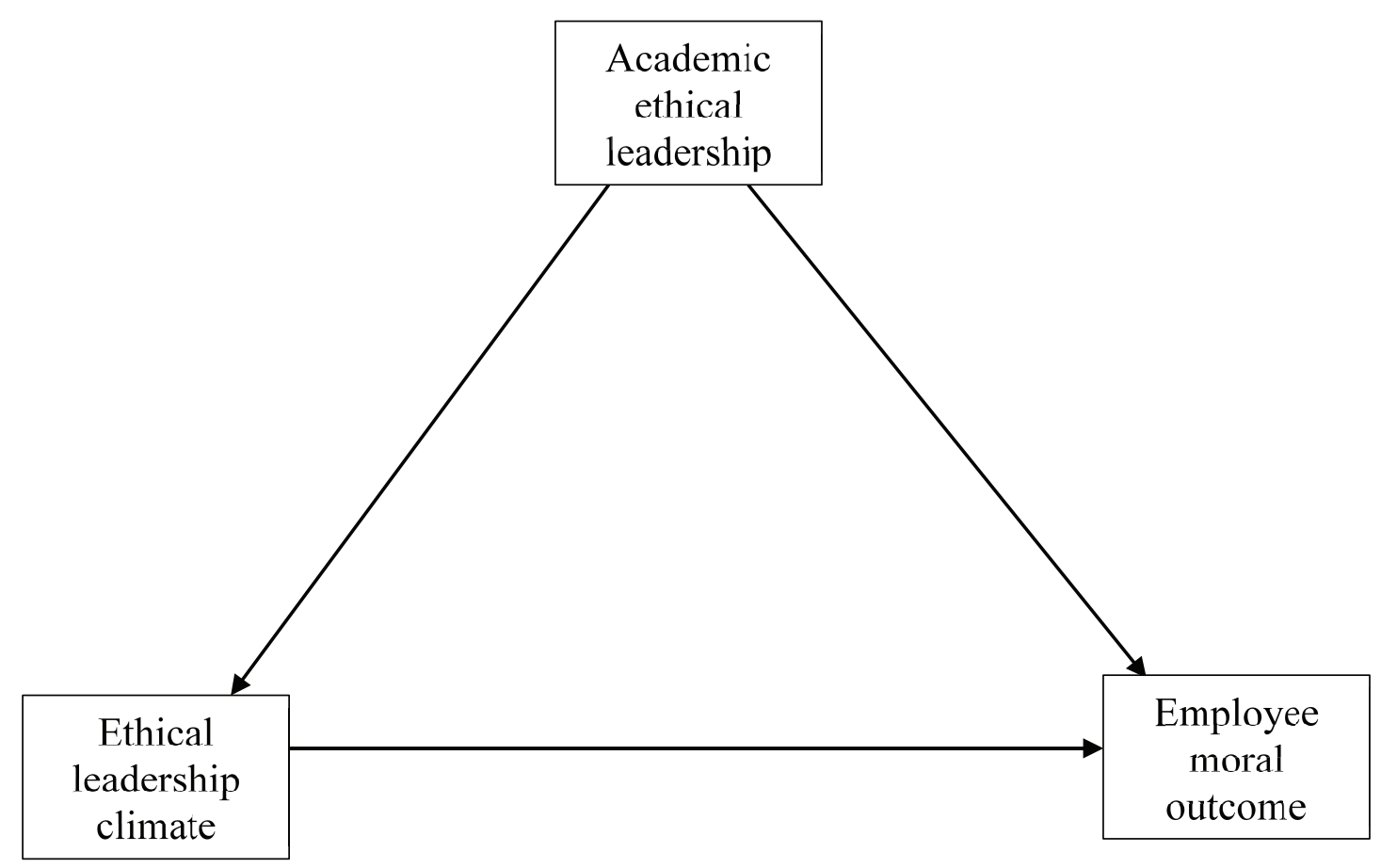

Figure 1: The Research Framework.

\section{Research Methods}

The study employs the refined instrument of Riggio et al. (2010) to measure virtuebased academic leadership construct. Although, De Hoogh \& Den Hartog (2008) argued ethical leadership to be multidimensional, nevertheless, drawing from Riggio et al. (2010), virtue-based dimension to assessing ethical leadership is intimately related to one another. In this study, measured in terms of moral consciousness created by top academic leaders as indicated in Hasnah et al. (2017) is the academic ethical climate while academic employee moral outcome covers four interdependent perspectives (moral motivation, moral sensitivity, moral judgment, and moral character) measurement of Rest \& Thoma (1985). In this study, employee moral outcome is used interchangeably with employee moral effectiveness and denotes the moral positioning of subordinates to take moral actions. The participants in the survey are lecturers in a public university in Nigeria. The lecturers participated voluntarily and were asked to fill out the questionnaire in confidant without discussion with colleagues. Out of the distributed 245 surveys, only 182 responses were usable and employed in the study. The 182 responses employed in the study is adequate as it is well above the 111-sample size requirement indicated in the G-power analysis with medium effect size, alpha level of 0.05 , and actual power of 0.95 . The study does not assume the normal 
distribution of the data. The partial least squares structural equation modeling (PLSSEM) technique was used to analyze the hypothesized relationships in the study. The measurement and the structural model need assessment by the rule associated with PLS-SEM (Hair, Hult, Ringle, \& Sarstedt, 2017). The measurement model which entails the evaluation of the validity and reliability of the construct measures was evaluated based on reflective measurement theory. Expected in the study is the correlations of all the indicators of the three constructs. Going by the reflective measurement criteria, assessed in the study is indicator reliability, internal consistency reliability, convergent validity, and discriminant validity. The structural model assessment draws on the 5000 bootstrap samples procedure (Hair et al., 2017) to test the significance of the hypothesized relationships at a 5\% probability of error level in the study. Apart from checking the significance of the path coefficients, in evaluating the structural model in this study, considered is the coefficient of determination $\left(R^{2}\right)$, the model predictive relevance and $\mathrm{f}^{2}$ effect sizes.

\section{Result}

\subsection{Measurement model assessment}

From Table 1, the internal consistency reliability using composite reliability (CR) criterion indicates a satisfactory level of reliability $(>0.70)$. Also, the convergent validity which assesses the extent to which a measure correlates positively with alternative measures of the same constructs is satisfactory on the construct level since all values are above the 0.50 minimum threshold using average variance extracted (AVE) as a criterion in the study. On the indicator level (see Table 1), using the outer loadings of the indicators, the indicator reliability is satisfactory $(>0.70)$ also. Deleted items are ELC4, ELC6, AEL1, and AEL4. Please, note that items $>0.40$ but $<0.70$ were not deleted as deletion does not increase the AVE and CR measures above threshold (Hair Jr, Sarstedt, Hopkins, \& Kuppelwieser, 2014). Discriminant validity is assessed in the study based on FornellLarcker criterion in (Hair Jr et al., 2014). Overall, the square roots of the AVEs for the reflective constructs are all higher than the correlations of these constructs with other latent variables in the path model (Table 2). The result from the assessment of the discriminant validity in this study implies that it is satisfactory as each construct is unique and captures phenomena not represented by other constructs. Overall, based on the specific rule of thumb for reflective measurement model, the measurement characteristics of the three constructs are valid and reliable. 
TABLE 1: Summary of the Measurement Model Assessment.

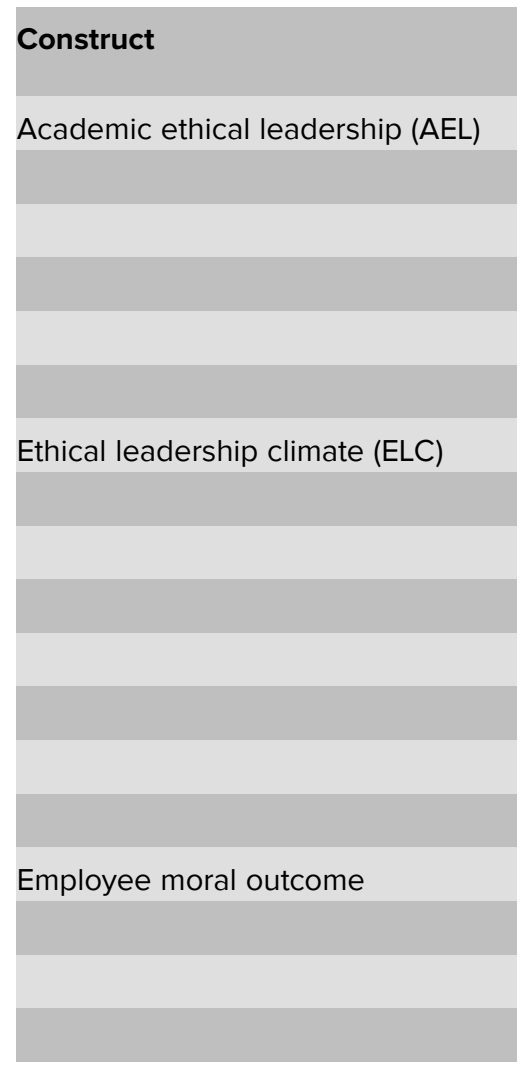

\begin{tabular}{|c|c|}
\hline Item & loadings \\
\hline AEL2 & 0.684 \\
\hline AEL3 & 0.707 \\
\hline AEL5 & 0.696 \\
\hline AEL6 & 0.765 \\
\hline AEL7 & 0.735 \\
\hline AEL8 & 0.761 \\
\hline ELC1 & 0.796 \\
\hline ELC10 & 0.795 \\
\hline ELC2 & 0.795 \\
\hline ELC3 & 0.792 \\
\hline ELC5 & 0.704 \\
\hline ELC7 & 0.75 \\
\hline ELC8 & 0.83 \\
\hline ELC9 & 0.756 \\
\hline EMO1 & 0.739 \\
\hline EMO2 & 0.855 \\
\hline EMO3 & 0.814 \\
\hline EMO4 & 0.816 \\
\hline
\end{tabular}
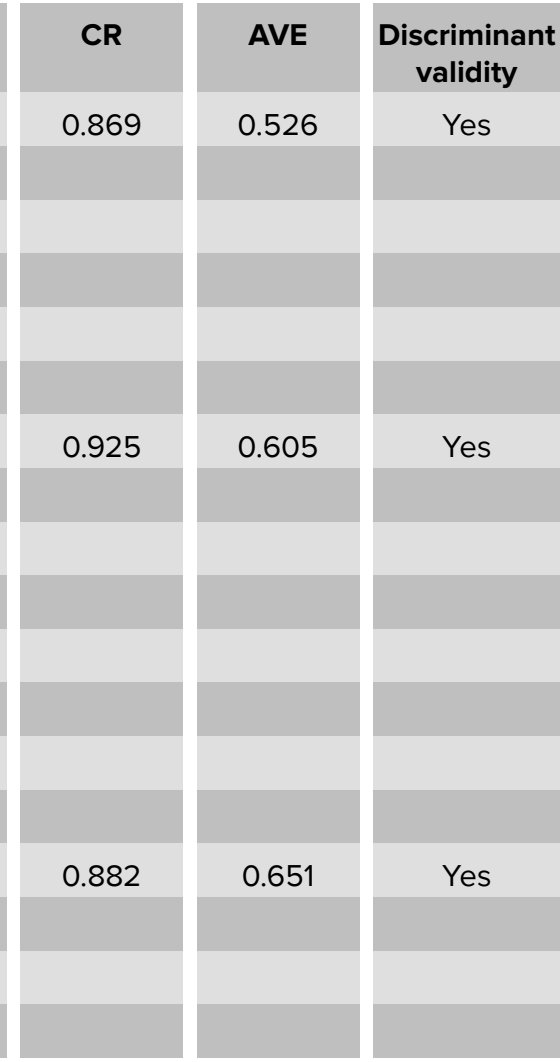

TABLE 2: Discriminant Validity.

\begin{tabular}{l|c|c|} 
& \multicolumn{3}{c}{ Fornell-Larcker criterion } \\
\hline Academic ethical & $\begin{array}{c}\text { Ethical leadership } \\
\text { climate }\end{array}$ & $\begin{array}{c}\text { employee moral } \\
\text { leadership }\end{array}$ \\
\hline outcome
\end{tabular}

\subsection{Structural model assessment}

\subsubsection{Hypotheses testing}

Going by Hair Jr et al. (2014) on structural model assessment procedure, the result (Table 3), using VIF guidelines threshold of below 5.00, indicating that there is no collinearity problem as all the measures are below 5.00 stipulated threshold. The result (direct, indirect and total effects) in table 3 represent the hypothesized relationships among the constructs in the study. $\mathrm{H} 1$ states that academic ethical leadership has a positive influence on employee moral outcome. The result indicates that academic ethical leadership is significantly (Beta $=0.202$, $t$-value $=2.493, p$-value $=0.006$ ) related 
to employee moral outcome and therefore contribute to explaining employee moral outcome. Thus, supported in this study is $\mathrm{H} 1$. On the direct relation between academic ethical leadership and ethical leadership climate, academic ethical leadership is significantly (Beta $=0.629, \mathrm{t}$-value $=10.933, \mathrm{p}$-value $=0.000$ ) related to ethical leadership climate and therefore contribute to explaining ethical climate. Thus, supported in the study is $\mathrm{H} 2$ which states that academic ethical leadership positively impacts ethical leadership climate.

Another direct relationship considered in the research is $\mathrm{H} 3 . \mathrm{H} 3$ indicates that ethical leadership climate positively influences employee moral outcome. The result suggests that ethical leadership climate is positive and significantly (Beta $=0.486$, t-value $=6.617, p$ value $=0.000$ ) related to employee moral outcome and therefore contribute to explaining employee moral outcome. $\mathrm{H} 4$ suggests that academic ethical leadership indirectly influences employee moral outcome through ethical leadership climate. The outcome of testing the indirect relationship posit that academic ethical leadership is positive and significantly $(B e t a=0.306$, $\mathrm{t}$-value $=5.059, \mathrm{p}$-value $=0.000)$ related to employee moral outcome and therefore contribute to indirectly explaining employee moral outcome. Hence, $\mathrm{H} 4$ is duly supported in the study. Overall, exploring the differential impact of the two drivers construct in the study, the total effect (see Table 3) shows that compared to ethical leadership climate, academic ethical leadership has a higher influence on employee moral outcome.

\subsubsection{Coefficient of determination, predictive relevance and effect sizes}

Apart from testing the hypothesized relationships, the study employed the coefficient of determination ( $R^{2}$ value) to evaluate the model predictive accuracy. The $R^{2}$ values in the research (see Table 3) is acceptable as academic ethical leadership explains 39.5 percent of the variation in ethical leadership climate while academic ethical leadership and ethical leadership climate jointly explain 40 percent amount of variance in employee moral outcome. Going by Hair Jr et al. (2014), the model's predictive accuracy is moderate. Using effect size $\mathrm{f}^{2}$ as a criterion to assess the substantive impacts on the endogenous construct (see Table 3), the impact of academic ethical leadership on ethical leadership climate is robust and ethical leadership climate impact on employee moral outcome is moderate while that of academic ethical leadership influence on employee moral outcome is weak. In addition to evaluating the magnitude of the $\mathrm{R}^{2}$ values in this study, the Stone-Geisser's $Q^{2}$ value is employed to evaluate the model's predictive relevance. The result (See Table 3) from the structural model assessment in 
the study indicate that the $Q^{2}$ values for the endogenous reflective constructs are more substantial than zero and therefore implies that the model exhibit predictive relevance. It is worthy of mentioning that this study did not assess the global goodness of fit (GoF) as Henseler and Sarstedt (2012) argued that the GoF for PLS does not represent an appropriate measure and should not be employed unless in a PLS multigroup analysis (PLS-MGA). Figure 2 is a summary of the measurement and structural model assessment.

TABLE 3: Summary of the Structural Model.

Hypothesized relationship
Academic ethical leadership ->
Ethical leadership climate
Academic ethical leadership ->
employee moral outcome
Ethical leadership climate ->
employee moral outcome
Academic ethical leadership ->
Ethical leadership climate ->
employee moral outcome
Ethical leadership climate
employee moral outcome
Academic ethical leadership ->
Ethical leadership climate
Academic ethical leadership ->
employee moral outcome
Ethical leadership climate ->
employee moral outcome
-

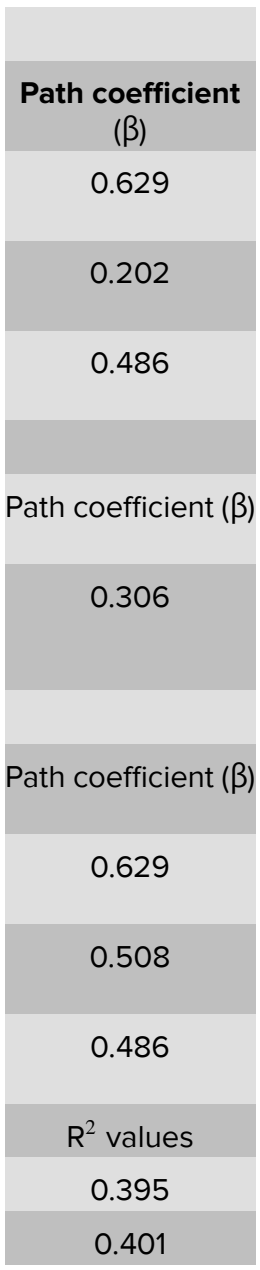

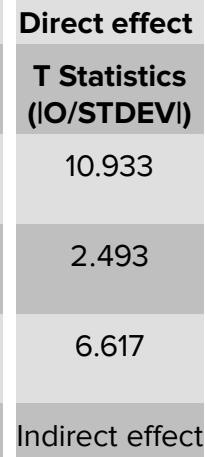

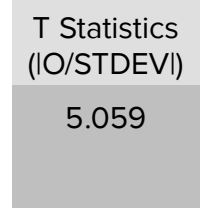

Total effect

T Statistics (IO/STDEVI)

10.933

\begin{tabular}{c}
9.595 \\
\hline 6.617 \\
\hline$Q^{2}$ \\
\hline 0.208 \\
0.231 \\
\hline
\end{tabular}

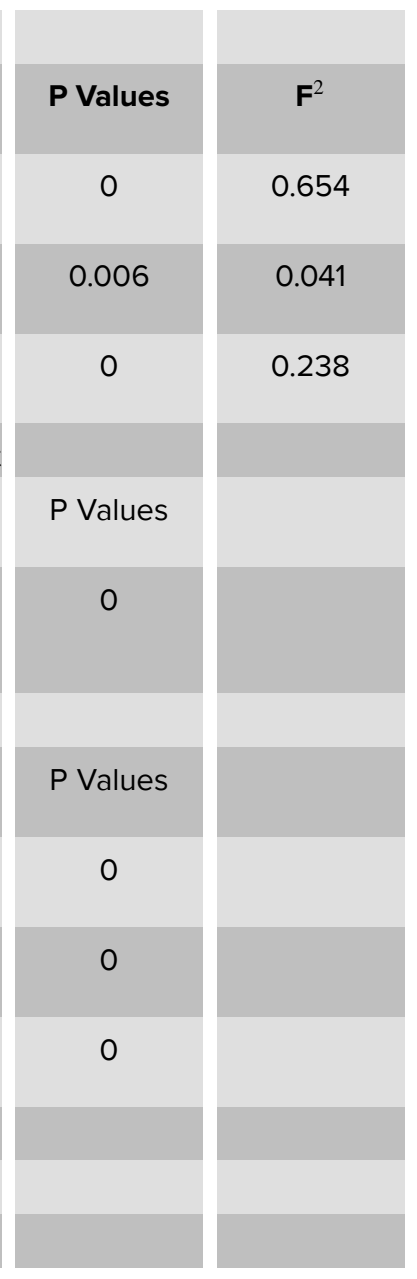

\section{Discussion and Implications}

Academic subordinates with strong moral inclinations, if they have academic leaders that stress ethics in meeting up with deadlines and set targets about their job function may not be involved in academic misconduct or wrongly display attitudes. On the impact of virtue-based ethical leadership on employee moral effectiveness, the study arrived at a positive direct relationship. The result suggests the critical role of virtues in assessing academic ethical leadership social influence on employee moral motivation, 


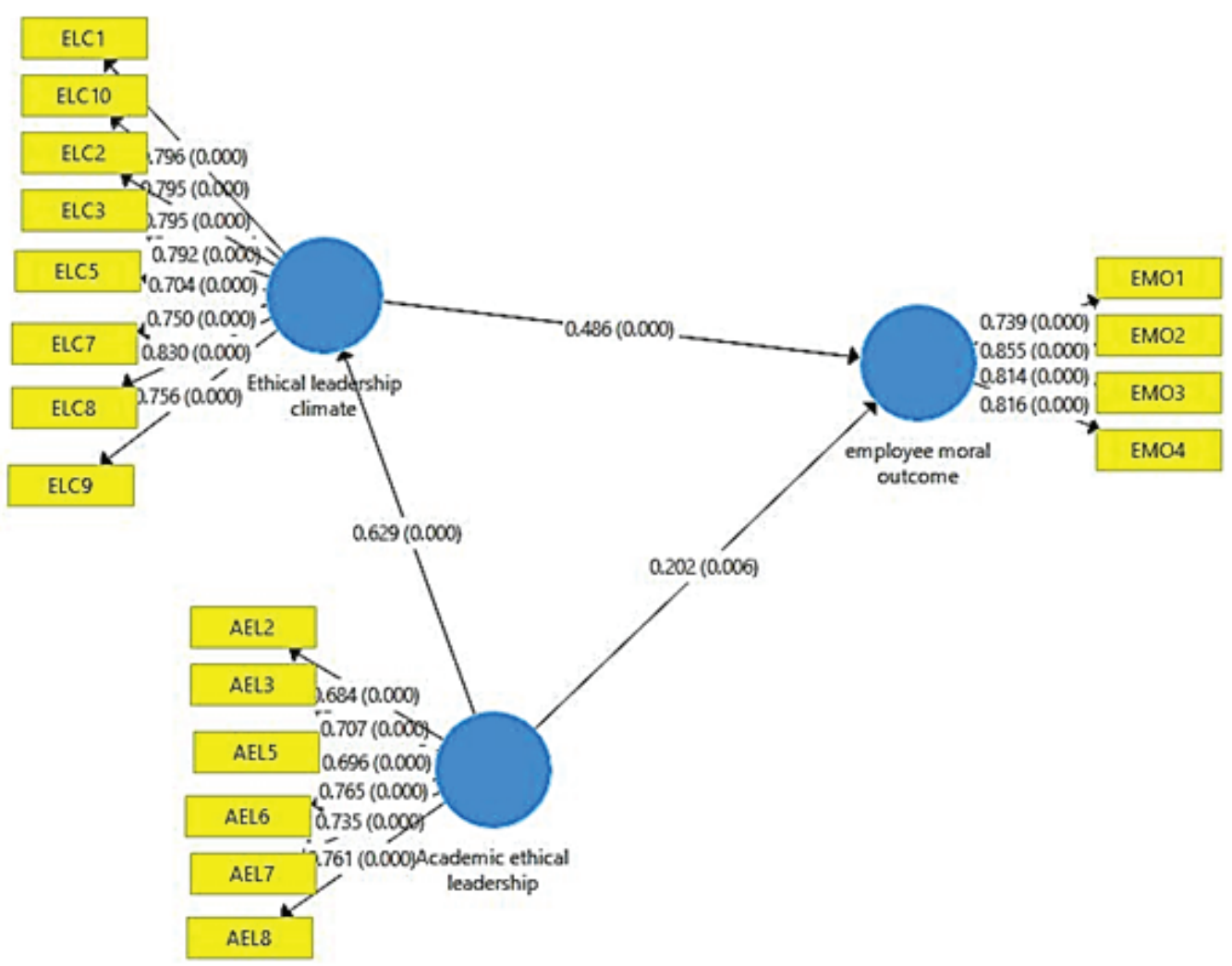

Figure 2: Structural Model.

moral sensitivity. This finding agrees with SLT that posit that observed moral fosters moral attitudes and prior works that argued leaders are role models for an employee to follow on moral matters since they possess high ethical and moral virtues (Hunter et al., 2013; Rest \& Thoma, 1985; Riggio et al., 2010). Therefore, the study contributes to social learning theory and existing works on ethical leadership in literature.

Haron et al. (2017) intimate that the ethical tone at top leadership is a vital determinant of ethical behaviors in organizations. In this study, the impact of ethical leadership climate on the ethical effectiveness of subordinate indicates a positive relationship based on a social learning perspective. This finding is consistent with social learning theory that suggests that for anyone to embark on moral attitudinal behavior, a social learning climate must be present (Brown et al., 2005). The finding implies that to enhance the moral performance of academic subordinates; it is vital for academic bodies to emphasize the ethical tone capabilities of academic leaders. Thus, educational policymakers can explore leaders to weaken the effect of academic employee unethical conduct.

An ethical leader that exhibits the cardinal virtues of fortitude, temperance, justice, and prudence according to Riggio et al. (2010), will create an ethical tone for necessary ethical decision making in institutions (Haron et al. 2017). Another finding from this study 
suggests that virtue-based ethical leadership positively influences ethical leadership climate in institutions. The result is consistent with prior literature (Riggio et al., 2010) that indicated that a virtue-based approach is a valuable tool for the assessment of ethical leadership. Based on social learning theory (SLT), this study argued that observation occurs before learning because, without the display of moral virtues by leaders, a learning environment cannot be created for an employee to learn morally from their leaders. The practical implication is that institutional ethical policymakers especially in Africa, can utilize a characterological perspective to enhance the ethical climate in institutions and mitigate the effects of unethical conducts in the academic.

One of the findings from the study indicates that virtue-based ethical leadership indirectly impacts employee moral effectiveness through ethical leadership climate. Therefore, institutions who want to influence their ethical climate and at the same time influence their subordinate moral behavior might consider selecting top leaders based on their virtues and not just their academic qualifications. The practical implication of the positive finding is that organizations may consider moral leadership development along with prudence, judgment, temperance, and justice as crucial components of virtues (Riggio et al., 2010) to manipulate workplace academic moral behaviors. This finding is consistent with social learning theory that indicates that people behave the way they do as a result of observation and learning occurrence and prior literature (Aristotle, 2006) that suggest moral habits makes a moral character. Overall, educational ethical policymakers especially in Africa should take cognizance of the differential impact of academic ethical leadership and ethical leadership climate on employee moral positioning when making policies in the institution of higher learning.

\section{Conclusion}

Indeed, academic leaders play significant ethical role as their moral habits (ethical virtues and tones) influences moral outcomes (employee moral effectiveness). This study provides empirical insight into the link between virtue-based academic leadership and academic employee morale result together with the role played by ethical leadership climate in the underlying relationships based on social learning theory (SLT) in an African context. The findings from this study provide evidence that virtue-based academic ethical leadership directly and indirectly socially influence proper employee positioning for moral actions via ethical tone enabled by leaders. As both the virtue and ethical tone-based leaders significantly contribute to the employee moral status, institutions in Africa can utilize the perspectives in their social network to stimulate employee moral 
academic behaviors in the workplace and address unethical practices. The research is limited in that the conclusion drawn from this study is grounded on only a country sample context in Africa. Consequently, researchers are encouraged to validate the findings across different countries to aid better understanding and generalizability in the future.

\section{Acknowledgement}

We would like to thank Yayasan Bank Rakyat for the financial support by sponsoring this paper to be presented in the FGIC $2^{\text {nd }}$ Conference on Governance and Integrity 2019.

\section{References}

[1] Abboud, M. J., Wu, G., Pedneault, A., Stohr, M. K., \& Hemmens, C. (2017). Educator Sexual Misconduct: A Statutory Analysis. Criminal Justice Policy Review, 0, 1-10. https://doi.org/10.1177/0887403418806564

[2] Akere, R. L., Sevell, E. A., \& Stewart, E. A. (2016). Social Learning Theory. In A. R. Piquero (Ed.), Wiley Handbooks in Criminology and Criminal Justice (pp. 230-240). Wiley Blackwell.

[3] Aristotle. (2006). Nicomachean Ethics. W. D. Ross Oxford: Clarendon Press. Retrieved from http://nothingistic.org/library/aristotle/nicomachean/

[4] Ayodele, F. O., Yao, L., \& Haron, H. (2018). Promoting Ethics and Integrity in Management Academic Research: Retraction Initiative. Science and Engineering Ethics, 1-26. https://doi.org/10.1007/s11948-017-9941-z

[5] Bagozzi, R. P., Sekerka, L. E., \& Sguera, F. (2018). Understanding the consequences of pride and shame: How self-evaluations guide moral decision making in business. Journal of Business Research, 84(November 2017), 271-284. https://doi.org/10.1016/ j.jbusres.2017.11.036

[6] Bouckenooghe, D., Zafar, A., \& Raja, U. (2015). How Ethical Leadership Shapes Employees' Job Performance: The Mediating Roles of Goal Congruence and Psychological Capital. Journal of Business Ethics, 129(2), 251-264. https://doi.org/ 10.1007/s10551-014-2162-3

[7] Brown, M. E., \& Treviño, L. K. (2006). Ethical leadership: A review and future directions. Leadership Quarterly, 17(6), 595-616. https://doi.org/10.1016/j.leaqua. 2006.10.004 
[8] Brown, M. E., Treviño, L. K., \& Harrison, D. A. (2005). Ethical leadership: A social learning perspective for construct development and testing. Organizational Behavior and Human Decision Processes, 97(2), 117-134. https://doi.org/10.1016/j. obhdp.2005.03.002

[9] De Hoogh, A. H. B., \& Den Hartog, D. N. (2008). Ethical and despotic leadership, relationships with leader's social responsibility, top management team effectiveness and subordinates' optimism: A multi-method study. Leadership Quarterly, 19(3), 297311. https://doi.org/10.1016/j.leaqua.2008.03.002

[10] Grimes, D. R., Bauch, C. T., loannidis, J. P. A., \& Grimes, D. R. (2018). Modelling science trustworthiness under publish or perish pressure. Royal Society Opens, 1-14.

[11] Hair, J. F., Hult, G. T. M., Ringle, C. M., \& Sarstedt, M. (2017). A Primer on Partial Least Squares Structural Equation Modeling (PLS-SEM) SECOND EDITION (Second edi). Los Angeles: SAGE.

[12] Hair Jr, J. F., Sarstedt, M., Hopkins, L., \& Kuppelwieser, V. G. (2014). Partial least squares structural equation modelling (PLS-SEM) An emerging tool in business research. European Business Review, 26(2), 106-121.

[13] Haron, H., Ismail, I., Zamli, K.Z., Saidin, S.Z., Darun, M.R., Yao, L., Min, L.K., Abdullah, A., Saleh, S.M., Ishak, N.K. (2017). ISo 37001: 2016 Anti-Bribery Management System (ABMS): The development of measurement and preliminary study of three organizations. Universiti Malaysia Pahang, 1-255.

[14] He, H., Zhu, W., \& Zheng, X. (2014). Procedural justice and employee engagement: Roles of organizational identification and Moral Identity Centrality. Journal of Business Ethics, 122(4), 681-695. https://doi.org/10.1007/s10551-013-1774-3

[15] Hoch, J. E., Bommer, W. H., Dulebohn, J. H., \& Wu, D. (2018). Do Ethical, Authentic, and Servant Leadership Explain Variance Above and Beyond Transformational Leadership? A Meta-Analysis. Journal of Management, 44(2), 501-529. https://doi. org/10.1177/0149206316665461

[16] Hunter, E. M., Neubert, M. J., Perry, S. J., Witt, L. A., Penney, L. M., \& Weinberger, E. (2013). Servant leaders inspire servant followers: Antecedents and outcomes for employees and the organization. Leadership Quarterly, 24(2), 316-331. https://doi. org/10.1016/j.leaqua.2012.12.001

[17] Hyytinen, H., \& Löfström, E. (2017). Reactively, Proactively, Implicitly, Explicitly? Academics' Pedagogical Conceptions of how to Promote Research Ethics and Integrity. Journal of Academic Ethics, 15(1), 23-41. https://doi.org/10.1007/s10805016-9271-9 
[18] Kalshoven, K., Den Hartog, D. N., \& De Hoogh, A. H. B. (2011). Ethical leadership at work questionnaire (ELW): Development and validation of a multidimensional measure. Leadership Quarterly, 22(1), 51-69. https://doi.org/10.1016/j.leaqua.2010. 12.007

[19] Leroy, H., Segers, J., van Dierendonck, D., \& den Hartog, D. (2018). Managing people in organizations: Integrating the study of HRM and leadership. Human Resource Management Review, 28(3), 249-257. https://doi.org/10.1016/j.hrmr.2018.02.002

[20] Lewis, E. (2017). A Global Perspective of Transformational Leadership and Organizational Development. Journal of Research Initiatives., 2(3), 5.

[21] Moore, C. (2015). Moral disengagement. Current Opinion in Psychology, 6, 199-204. https://doi.org/10.1016/j.copsyc.2015.07.018

[22] Reb, J., Narayanan, J., \& Chaturvedi, S. (2014). Leading Mindfully: Two Studies on the Influence of Supervisor Trait Mindfulness on Employee Well-Being and Performance. Mindfulness, 5(1), 36-45. https://doi.org/10.1007/s12671-012-0144-z

[23] Rest, J. R., \& Thoma, S. J. (1985). Relation of Moral Judgment Development to Formal Education. Developmental Psychology, 21(4), 709-714. https://doi.org/10.1037/00121649.21.4.709

[24] Riggio, R. E., Zhu, W., Reina, C., \& Maroosis, J. A. (2010). Virtue-based measurement of ethical leadership: The Leadership Virtues Questionnaire. Consulting Psychology Journal: Practice and Research, 62(4), 235-250. https://doi.org/10.1037/a0022286

[25] Riggio, R. E., Zhu, W., Reina, C., \& Maroosis, J. A. (2015). “Virtue-based measurement of ethical leadership: The Leadership Virtues Questionnaire": Correction to Riggio et al. (2010). Consulting Psychology Journal: Practice and Research, 67(1), 81. https: //doi.org/10.1037/cpb0000032

[26] Sidani, Y. M., \& Rowe, W. G. (2018). A reconceptualization of authentic leadership: Leader legitimation via follower-centered assessment of the moral dimension. Leadership Quarterly, 29(6), 623-636. https://doi.org/10.1016/j.leaqua.2018.04.005

[27] Sousa, M., \& van Dierendonck, D. (2017). Servant Leadership and the Effect of the Interaction Between Humility, Action, and Hierarchical Power on Follower Engagement. Journal of Business Ethics, 141(1), 13-25. https://doi.org/10.1007/ s10551-015-2725-y

[28] Walker, B. R., \& Jackson, C. J. (2017). Moral Emotions and Corporate Psychopathy: A Review. Journal of Business Ethics, 141(4), 797-810. https://doi.org/10.1007/s10551016-3038-5 
[29] Walumbwa, F. O., Mayer, D. M., Wang, P., Wang, H., Workman, K., \& Christensen, A. L. (2011). Linking ethical leadership to employee performance: The roles of leadermember exchange, self-efficacy, and organizational identification. Organizational Behavior and Human Decision Processes. https://doi.org/10.1016/j.obhdp.2010.11. 002

[30] Xu, A. J., Loi, R., \& Ngo, H. yue. (2016). Ethical Leadership Behavior and Employee Justice Perceptions: The Mediating Role of Trust in Organization. Journal of Business Ethics, 134(3), 493-504. https://doi.org/10.1007/s10551-014-2457-4 